\title{
che?
}

\section{Minha casa é aqui! Percepções dos beneficiários do Minha Casa Minha Vida}

\author{
Polliana de Luna Nunes Barreto \\ Doutora em Educação - UFCA \\ pollliana.luna@ufca.edu.br \\ https://orcid.org/0000-0003-3936-6002 \\ Cirlany Sousa Matos \\ Graduanda em Administração Pública - UFCA \\ matos.cirlany@aluno.ufca.edu.br \\ https://orcid.org/0000-0002-2725-1358
}

\section{Resumo}

Este artigo discute a implementação do programa Minha Casa Minha Vida em BarbalhaCE. Para tanto, usa dados relativos à dinâmica discursiva dos beneficiários dessa política e recorre ao arcabouço documental que alicerça suas ações. Nessa arena de enfrentamento, os atores expõem as dificuldades de implementação e as deficiências do processo de tomada de decisão desse programa. Devemos considerar o impacto das políticas habitacionais no desenvolvimento sustentável das cidades e a consequente ampliação das oportunidades sociais para seus habitantes, daí a relevância científica e política deste estudo de caso, de abordagem qualiquantitativa, que, valendo-se das técnicas de levantamento bibliográfico, levantamento documental e diário de campo, além da aplicação de uma entrevista semiestruturada, analisou, com foco no Conjunto Residencial Raimundo Pedro da Cruz, no Município de Barbalha, o processo de implementação de uma política habitacional que coloca em relevo as consonâncias e as dissonâncias de tal processo.

Palavras-chave política habitacional; programa minha casa minha vida; participação social; desenvolvimento sustentável das cidades.

Conhecer: debate entre o público e o privado 2020, Vol. 10, no 25

ISSN 2238-0426

DOI https://doi.org/10.32335/2238-0426.2020.10.25.3036

Licença Creative Commons Atribuição (CC BY 4.0)

Data de submissão 20 abr 20

Data de publicação 03 ago 20 


\title{
My home is here! Perceptions of Minha Casa Minha Vida Program's beneficiaries
}

\begin{abstract}
This article discusses the implementation of the Minha Casa Minha Vida Program in Barbalha, Ceará, Brazil. To do this, it uses data related to the discursive dynamics of this policy's beneficiaries and resorts to the documentary framework that underlies its actions. In this confrontation arena, the players expose the implementation difficulties and the deficiencies in the decision-making process of this program. We must consider the impact of housing policies on the sustainable development of cities and the consequent expansion of social opportunities for their inhabitants, hence the scientific and political relevance of this case study, with a qualiquantitative approach, which, relying on the techniques of bibliographic survey, documentary survey, and field diary, in addition to the application of a semi-structured interview, analyzed, focusing on the Raimundo Pedro da Cruz Residential Complex, in the municipality of Barbalha, the process of implementing a housing policy that highlights the consonances and dissonances of such a process.
\end{abstract}

Key words housing policy; minha casa minha vida program; social participation; sustainable development of cities.

\section{iMi casa es aquí! Percepciones de los beneficiarios del Programa Minha Casa Minha Vida}

\section{Resumen}

Este artículo discute la implementación del Programa Minha Casa Minha Vida en Barbalha, Ceará, Brasil. Para hacer esto, utiliza datos relacionados con la dinámica discursiva de los beneficiarios de esta política y recurre al marco documental que subyace en sus acciones. En esta arena de confrontación, los actores exponen las dificultades de implementación y las deficiencias del proceso de toma de decisiones de este programa. Debemos considerar el impacto de las políticas de vivienda en el desarrollo sostenible de las ciudades y la consiguiente expansión de las oportunidades sociales para sus habitantes, de ahí la relevancia científica y política de este estudio de caso, con un enfoque cualicuantitativo, que, basándose en las técnicas de encuesta bibliográfica, encuesta documental y diario de campo, además de la aplicación de una entrevista semi-estructurada, analizó, centrándose en el Complejo Residencial Raimundo Pedro da Cruz, en el municipio de Barbalha, el proceso de implementación de una política de vivienda que resalta las consonancias y las disonancias de tal proceso.

Palabras clave política de vivienda; programa minha casa minha vida; participación social; desarrollo sostenible de las ciudades. 


\title{
Ma maison est ici! Perceptions des bénéficiaires du Programme Minha Casa Minha Vida
}

\begin{abstract}
Résumé
Cet article traite de la mise en œuvre du Programme Minha Casa Minha Vida à Barbalha, Ceará, Brésil. Pour ce faire, il utilise des données liées à la dynamique discursive des bénéficiaires de cette politique et recourt au cadre documentaire qui sous-tend ses actions. Dans cette arène de confrontation, les acteurs exposent les difficultés de mise en œuvre et les carences du processus décisionnel de ce programme. Il faut considérer l'impact des politiques du logement sur le développement durable des villes et l'expansion conséquente des opportunités sociales pour leurs habitants, d'où la pertinence scientifique et politique de cette étude de cas, avec une approche qualiquantitatif, qui, basée sur les techniques d'enquête bibliographique, d'enquête documentaire et de journal de terrain, en plus de l'application d'un entretien semi-structuré, a analysé, en se concentrant sur le Complexe Résidentiel Raimundo Pedro da Cruz, dans la municipalité de Barbalha, le processus de mise en œuvre d'une politique de logement qui met en évidence les consonances et les dissonances d'un tel processus.
\end{abstract}

Mots-clés politique du logement; programme minha casa minha vida; participation sociale; développement durable des villes.

\section{Introdução}

O crescimento econômico do Brasil e a consequente urbanização de seu território ocorreram de modo desigual e irregular em relação a várias categorias. O território brasileiro se transformou à luz da especulação do mercado, que dirigiu, por sua vez, os rumos das políticas públicas. Dessa forma, ao longo do processo de colonização do país, observamos o crescimento exponencial das regiões Sul e Sudeste e o declínio de outras localidades, demonstrando um desnível na elaboração da política de desenvolvimento nacional. Igualmente, nossas zonas urbanas e rurais são encaradas de modo dissociado e o crescimento desordenado dessas áreas impacta diretamente os meios de vida e a sustentabilidade de suas comunidades.

A industrialização tardia e pautada em um frágil mercado consumidor e em um parque industrial dependente do capital externo trouxe a conotação que o modelo de crescimento econômico do país teria ao longo do século XX. A consolidação das grandes cidades, especialmente a partir da década de 1930 (Costa \& Venâncio, 2016), como local de oferta de empregos nas indústrias ocasionou o êxodo rural e a desorganização do trabalho no campo, ao mesmo tempo que aprofundou as desigualdades sociais na zona urbana.

Junto com essas mudanças, por outro lado, revelaram-se as mazelas da sociedade brasileira, dentre as quais se destaca a questão da moradia. Na esfera federal, sucessivos governos buscaram soluções para reduzir o déficit habitacional, por meio da implementação de iniciativas habitacionais como o Banco Nacional de Habitação (em 1964) e a Política de Habitação: Ações do Governo Federal (de 1995 a 1998). Respectivamente, essas ações tiveram dificuldade para lograrem continuidade, ora devido à inadimplência, ora por não 
atingirem a população de baixa renda ou, ainda, por priorizarem interesses privados (Santos, 1990).

O crescimento populacional e a inexistência de uma política habitacional eficaz aumentou o fosso entre aqueles que tinham e aqueles que não tinham acesso à moradia. Como apontam Costa e Venâncio (2016), no Brasil, a crise habitacional decorre de um desenvolvimento econômico pautado pela acumulação de riqueza e desconsidera as questões sociais, agravando o impacto ambiental diante da ausência de políticas públicas direcionadas ao desenvolvimento sustentável do meio urbano.

Diante dessa realidade, é comum que os indivíduos sem capacidade financeira para adquirir uma residência acabem promovendo a ocupação de terrenos de modo irregular, sem as mínimas condições de segurança e higiene. Assim, na prática, o direito social à moradia digna disposto na Constituição da República Federativa do Brasil (CF, 1988) se torna uma norma sem força legal, tendo em vista a inaplicabilidade do pleno exercício de tal direito.

A moradia digna propriamente dita passou a ser um direito social por meio da Emenda Constitucional n. 90 (EC n. 90, 2015), indicando que, na forma da CF (1988), são direitos sociais a educação, a saúde, a alimentação, o trabalho, a moradia, o transporte, o lazer, a segurança, a previdência social, a proteção à maternidade e à infância e a assistência aos desamparados.

O Comitê dos Direitos Econômicos, Sociais e Culturais da Organização das Nações Unidas (ONU) define a moradia digna como aquela que apresenta condições adequadas de salubridade e de segurança, além de um tamanho mínimo considerado habitável. Deve ser dotada de instalações sanitárias adequadas e atendida pelos serviços públicos essenciais, dentre os quais água encanada, coleta de lixo, energia elétrica e esgoto. Para a ONU, a moradia digna vai além da mera construção que abriga um núcleo familiar, ou seja, não se resume a um conjunto de paredes, devendo prover condições adequadas para a convivência salubre e segura, com acesso aos equipamentos sociais e comunitários básicos - escolas públicas, iluminação pública, pavimentação pública, postos de saúde, praças de lazer, transporte coletivo etc. (BRASIL,2013).

Este artigo discute a implementação do programa Minha Casa Minha Vida em Barbalha-CE. Para tanto, usa dados relativos à dinâmica discursiva dos beneficiários dessa política e recorre ao arcabouço documental que alicerça suas ações. Nessa arena de enfrentamento, os atores expõem as dificuldades de implementação e as deficiências do processo de tomada de decisão desse programa. Devemos considerar o impacto das políticas habitacionais no desenvolvimento sustentável das cidades e a consequente ampliação das oportunidades sociais para seus habitantes, daí a relevância científica e política deste estudo de caso, de abordagem qualitativa, que, valendo-se das técnicas de levantamento bibliográfico, levantamento documental e diário de campo, além da aplicação 
de uma entrevista semiestruturada, analisou, com foco no Conjunto Residencial Raimundo Pedro da Cruz, no Município de Barbalha, o processo de implementação de uma política habitacional que coloca em relevo as consonâncias e as dissonâncias de tal processo.

\section{Metodologia}

Criado em 2009, o programa Minha Casa Minha Vida constitui a principal política habitacional do Brasil, voltada à diminuição do déficit habitacional em nível nacional. Segundo Silva e Tourinho (2015), no período 2009-2014 foram contratadas 3,4 milhões de unidades habitacionais pelo programa. Para elaborar nossa análise com foco no Conjunto Residencial Raimundo Pedro da Cruz, no Município de Barbalha, usamos dados primários relativos à dinâmica discursiva dos beneficiários dessa política, colhidos por meio de diário de campo, de imagens fotográficas e da aplicação de uma entrevista semiestruturada, bem como do arcabouço documental que alicerça as ações.

As perguntas que nortearam esta pesquisa se voltaram aos reflexos de uma política pública de alcance nacional implementada em nível local. Assim, abordamos as seguintes questões:

- Qual é o perfil socioeconômico dos beneficiários do programa Minha Casa Minha Vida?

- Quais são os principais impactos dessa política na vida de seus beneficiários?

- Como o programa Minha Casa Minha Vida se caracteriza sob uma perspectiva comparada das localidades?

- Como os beneficiários do programa Minha Casa Minha Vida participam em sua implementação?

Tecnicamente, recorremos às metodologias de pesquisa bibliográfica e documental - esta apoiada em artigos sobre: a) a experiência do programa Minha Casa Minha Vida em outras localidades; b) o direito à moradia; e c) a segregação social. Foram realizadas consultas em bases de dados oficiais do Governo Federal, do Instituto Brasileiro de Geografia e Estatística (IBGE) e de sites de notícias. No âmbito exploratório, foram realizadas visitas in loco - em um primeiro momento, para conhecer a comunidade, realizar registros fotográficos e vivenciar o trânsito no local e em outros pontos do município. $\mathrm{Na}$ sequência, foram realizadas visitas às casas de alguns moradores que se dispuseram a falar sobre sua experiência no programa.

A seção "Resultados e discussão" deste artigo se estrutura em 4 subseções: a) "Política habitacional no Brasil: um panorama", que visa a mostrar como o programa Minha Casa Minha Vida é avaliado em outras regiões do Brasil, quais são os impactos dessas instalações nas áreas rurais e quais são as maiores complicações enfrentadas pelos moradores nessa realidade; b) "O programa Minha Casa Minha Vida e suas contradições" 
expõe as consonâncias e as dissonâncias entre a previsão legal e a efetiva aplicabilidade da política; c) "Barbalha-CE no mapa das políticas habitacionais" discute a cidade quanto à sua localização, sua economia e seus aspectos culturais, apresentando a partir dessa experiência o Conjunto Residencial Pedro Raimundo da Cruz, lócus de nossa investigação; e d) "Quem fala? A política habitacional e seus sujeitos" fecha a discussão dos resultados.

Por fim, constitui-se um breve retrospecto das abordagens elencadas e apresentam-se lacunas a observar a posteriori para consolidar as contribuições deste artigo.

\section{Resultados e discussão}

\section{Política habitacional no Brasil: um panorama}

Historicamente, a sociedade brasileira apresenta a tendência de compelir as populações de baixa renda para áreas afastadas, com o propósito de "afastar" a pobreza dos grandes centros. Podemos citar momentos específicos nos quais a política de contenção das populações esteve ligada à sua expulsão das áreas centrais dos municípios. J. M. Carvalho (1987) e Sevcenko (2003) trataram, respectivamente, de localizar o fenômeno das reformas urbanas no Rio de Janeiro.

A expulsão das camadas mais pobres da população em direção a espaços geográficos específicos não foi uma ação pontual do Sudeste brasileiro. Ao destacar a Seca de 1915 no Nordeste do país, constata-se que milhares de sertanejos foram deslocados de suas origens locais em busca da sobrevivência em centros urbanos (como Fortaleza-CE). Em face dessa realidade, o Governo Federal e o Governo do Estado do Ceará ergueram campos de concentração para impedir a chegada dos sertanejos à capital estadual cearense e, assim, prevenir a "miséria" nos centros urbanos do país (Neves, 1995).

Observa-se que o processo de segregação social é um dos fatores históricos do Brasil, com o Estado formalmente imbuído da proteção das populações, mas agindo ao arrepio de sua função precípua - em muitos casos, trata-se do principal mantenedor da pobreza e da desigualdade.

Foi sob essa perspectiva que emergiu o pensamento do geógrafo Milton Santos (1990, p. 31) a respeito das habitações construídas pelo Banco Nacional de Habitação (BNH) desde o ano de 1964: "as escolhas das terras para edificação dos conjuntos parece ter obedecido a um critério principal, o distanciamento do centro, figurado praticamente em todos os casos como um dado obrigatório".

Nesse sentido, aqui, empreendemos uma breve análise dos principais elementos comparativos sobre o programa Minha Casa Minha Vida em algumas localidades e em distintas regiões do país, a saber: a) Viçosa-MG (A. W. B. Carvalho \& Stephan, 2016); b) Salvador-BA (Menezes, 2015); c) Londrina-PR (Pagani, 2013); e d) Ponta de Pedra-AM (Rangel \& Montoia, 2015). 
O primeiro problema comum a todos os conjuntos habitacionais pesquisados consiste na escolha da localidade para sua implantação, já que se evidencia a especulação de grupos econômicos e políticos e a ausência de participação social por meio da escuta, além da interferência dos beneficiários diretos da política pública, como apontado por Menezes, a má localização dos conjuntos habitacionais como resultado da busca do empresariado por terras baratas ou sujeitas à valorização imobiliária”. (Menezes, 2015)

Assim, Andrade (2011) indica que o programa Minha Casa Minha Vida tem produzido uma significativa construção de conjuntos e condomínios habitacionais com localizações periféricas nas cidades, onde o preço da terra é mais baixo, mas com pouca ou nenhuma oferta de serviços.

A partir do fator localização se desencadeiam variados problemas relatados pela população, dentre eles a dificuldade de acesso a: a) hospitais; b) postos de saúde; c) transportes públicos; d) escolas; e) oportunidades de trabalho; e f) serviços públicos e privados diversos.

Os beneficiários destacam particular insatisfação quanto aos transportes públicos nos mais diversos municípios. A despeito da existência desses serviços na região, os moradores afirmam que o acesso a eles se mostra insuficiente e há excessiva demora nos percursos. Em Viçosa, Salvador, Londrina e Ponta de Pedra os indivíduos afirmam que os transportes só passam pela localidade em intervalos de 1 ou 2 horas, o que leva à superlotação dos veículos disponíveis.

O acesso às instituições de ensino constitui outro problema, pois não há escolas próximas à maioria dos conjuntos habitacionais e a chegada às salas de aula depende exclusivamente de ônibus escolares disponibilizados pelo poder público.

\footnotetext{
Em um território cuja população de crianças e adolescentes soma quase 50\%, não foi construída uma única unidade escolar. Um exemplo da fragilidade da gestão municipal é o fato de que, para garantir o acesso à educação para, aproximadamente, mil crianças, que não conseguiram vaga escolar nas proximidades de sua casa, a prefeitura paga, diariamente, $\mathrm{R} \$ 6.400,00 \mathrm{em}$ locação de ônibus, para transportar os alunos para 23 escolas do município (Folha de São Paulo, 2012).
}

Segundo os parâmetros definidos pelo programa Minha Casa Minha Vida, deveria ser garantido o acesso dos moradores dos conjuntos habitacionais às políticas de saúde, no entanto, a aplicabilidade desse princípio se mostra falha: os beneficiários do programa reclamam da falta de postos de saúde e hospitais próximos às suas residências e quando eles existem há constante falta de insumos e profissionais da saúde. A distância entre 
os conjuntos habitacionais e os serviços de saúde aumenta o tempo necessário para o atendimento e cria agravantes nos casos de emergência.

Em geral, nas localidades analisadas, segue-se uma tendência diante das insatisfações expostas pelos beneficiários. Segundo A. W. B. Carvalho e Stephan (2016), os fatores relatados levam ao isolamento da população dos conjuntos habitacionais em relação aos demais habitantes das cidades, o que reforça a segregação social historicamente percebida no Brasil e constitui objeto de estudo de várias áreas do conhecimento.

Todavia, mesmo com todas as objeções dos moradores dos conjuntos habitacionais às políticas públicas implementadas, os relatos dos beneficiários indicam que eles preferem a residência proporcionada pelo programa Minha Casa Minha Vida em vez de sua antiga moradia. Isso nos leva a refletir sobre o impacto da ausência de um espaço que se possa chamar de lar na dignidade das pessoas.

O que observamos no estudo de caso sobre o Município de Barbalha foi que o cenário do programa Minha Casa Minha Vida espelha as realidades do recorte bibliográfico. Os direitos sociais, objeto do art. 6 da CF (1988), que deveriam ser garantidos e efetivados pelo poder público, tornaram-se "expectativas" para os beneficiários - os quais exigem que a melhoria de suas condições de moradia seja acompanhada pela melhoria dos serviços sociais.

Além do exposto, como demonstra James Holston (2013), a democratização ampliou as disputas por direitos garantidos pelo arcabouço constitucional e as reivindicações dos movimentos de moradia. De fato, a democracia proporcionou uma arena pública de luta para alcançar as expectativas não atendidas e implementar as políticas públicas ausentes.

\section{O programa Minha Casa Minha Vida e suas contradições}

A crise econômica anunciada em 2008, a partir dos Estados Unidos da América (EUA), teve reflexos na economia global, causando especulação e instabilidade financeira no mundo inteiro. Foi nesse contexto que o governo brasileiro anunciou o programa Minha Casa Minha Vida no início de 2009. Ele surgiu com objetivos específicos em resposta à crise, dentre as quais: a) amenizar internamente os efeitos da crise econômica, por meio de incentivos e investimentos voltados a construtoras; e b) enfrentar o crescente déficit habitacional que há muito assola as cidades brasileiras (Pessoa, 2016).

Criado a partir da Lei n. 11.977 (2009), esse programa se caracteriza pela construção de residências para 3 faixas de renda familiar: a) faixa 1, destinada a famílias com renda até $R \$ 1.600,00$; b) faixa 2, para famílias com renda entre $R \$ 1.600,01$ e $R \$ 3.100,00$; e c) faixa 3, para famílias com renda entre $R \$ 3.100,01$ a $R \$ 5.000,00$. 
A faixa 1, conhecida como "Habitação de Interesse Social", constiuiu o objeto desta pesquisa. O desenrolar do projeto habitacional se dá, segundo Pessoa (2016), por meio da "oferta", ou seja, cabe às construtoras elaborar cada projeto e escolher o terreno para desenvolvê-lo. Nesse sentido, a política pública habitacional voltada às famílias de baixa renda parte da parceria entre instituições públicas e privadas, na qual o setor público assume papel secundário na tomada de decisões e não há qualquer espaço de interferência por parte dos beneficiários.

Para se enquadrar na faixa 1, os interessados deveriam atender a um perfil social: a) apresentarem renda familiar dentro do(s) limite(s) estabelecido(s); b) não disporem de imóvel próprio; c) viverem em área de risco; e d) comprovarem que pagam aluguel, entre outras exigências.

Considerando a predominância do setor privado na implementação do programa, assim como as informações obtidas sobre sua operação em localidades diversas, observamos paridade com alguns dos critérios estabelecidos pela Lei n. 11.977 (2009) e, ao mesmo tempo, disparidade com a prática cotidiana.

O art. 3ㅇ, § 1o, I, da Lei n. 11.977 (2009) contempla:

[...] a doação pelos Estados, pelo Distrito Federal e pelos Municípios de terrenos localizados em área urbana consolidada para implantação de empreendimentos vinculados ao programa.

Logo, depreende-se que tais áreas devem estar localizadas em zonas urbanas, mas vale notar a conversão de áreas rurais em áreas urbanas destinadas a tais empreendimentos, como alude a Lei n. 11.977 (2009):

\footnotetext{
Art. 5o-A. Para a implantação de empreendimentos no âmbito do PNHU, deverão ser observados:

I - localização do terreno na malha urbana ou em área de expansão que atenda aos requisitos estabelecidos pelo Poder Executivo federal, observado o respectivo plano diretor, quando existente;

$[\ldots]$
}

Prioritariamente, os critérios de escolha versam interesses privados, sendo perceptível a busca por terrenos distantes das áreas centrais e baratos, deslocando a população de baixa renda para locais remotos e instalando a infraestrutura básica no entorno desses 
terrenos, valorizando as áreas de acesso a eles, uma vez que o art. 5o-A da Lei n. 11.977 (2009) também estabelece a:

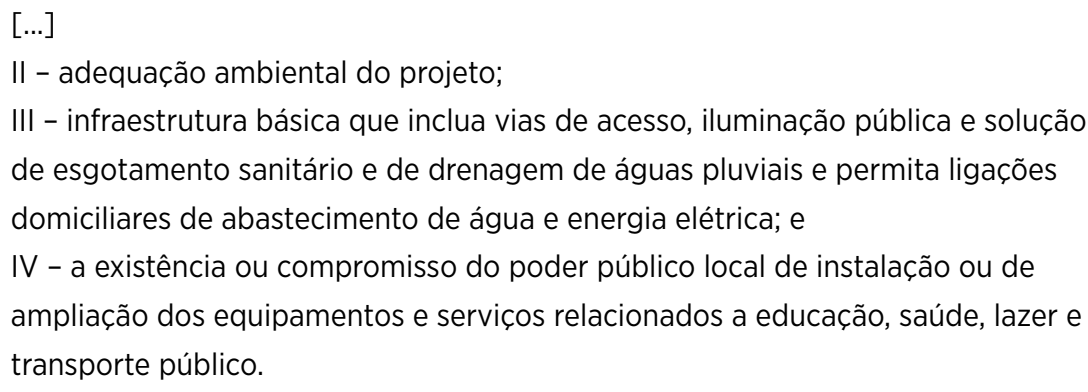

Por fim, trata-se de uma obrigação do poder público local oferecer aos moradores desses empreendimentos equipamentos básicos como escolas, postos de saúde, espaços de convivência, centros de assistência social e transportes públicos de qualidade a preços acessíveis. No entanto, o que se observou na pesquisa bibliográfica empreendida e no estudo de caso realizado foi o amplo desrespeito às normas supracitadas. Em todas as localidades analisadas neste estudo existem falhas estruturais decorrentes de má gestão por parte do poder público, caracterizando um claro descompasso entre as disposições legais e os serviços efetivamente oferecidos aos beneficiários do programa Minha Casa Minha Vida.

Destarte, evidencia-se a discrepância entre o que está previsto em lei e aquilo que se põe em prática. De modo comparativo, essas discrepâncias que se repetem entre os conjuntos habitacionais nas diversas localidades brasileiras refletem a existência de uma dinâmica estrutural de segregação social da pobreza.

\section{Barbalha-CE no mapa das políticas habitacionais}

O Município de Barbalha se localiza na Região Metropolitana do Cariri (RMC), no Estado do Ceará. A RMC é composta por 9 municípios, nos termos da Lei Complementar Estadual n. 78 (LCE n. 78, 2009). Os municípios de Juazeiro do Norte, Crato e Barbalha se destacam por sua expansão populacional e econômica e por sua rede de serviços públicos e privados.

Sob essa perspectiva, o Município de Barbalha, localizado na RMC, também é conhecido como a "Terra dos Verdes Canaviais" - referência simbólica ao auge de sua produção de cana-de-açúcar, que teve início na primeira metade do século XVIII (Gonçalves, 2011). Atualmente, Barbalha não vive do melaço da cana-de-açúcar, mas de uma rede de serviços de saúde, do turismo, da produção agrícola e, ainda, da indústria farmacêutica. 
Sua população foi estimada em 59.811 habitantes pelo Instituto Brasileiro de Geografia e Estatística (IBGE, 2010), ocupando a 7a posição em termos de índice de desenvolvimento humano (IDH) no Estado do Ceará.

A economia local se baseia na agricultura, sendo o município considerado um polo agrícola, com destaque para a produção de frutas, legumes, verduras e hortaliças. 0 comércio e os serviços locais pouco diversificados preservam algumas tradições, como a feira semanal. Em consonância com a RMC, Barbalha é referência no setor saúde, pois em seu território se encontra um polo regional de saúde para onde acorre um considerável número de moradores dos municípios cearenses em seu entorno e, também, dos estados que fazem divisa com o Ceará.

Nesse enquadramento, Barbalha assume destaque na análise das políticas públicas habitacionais. A formação da RMC trouxe consigo a expectativa de maior crescimento econômico, expansão urbana e geração de empregos, além do aumento da renda e dos investimentos em inúmeros setores, ainda que o debate sobre desenvolvimento sustentável tenha ficado à mercê das agendas locais.

Esses fatores impulsionam a migração de muitas famílias, de origem rural ou de municípios menores, para essa região. Concomitantemente, tal fenômeno migratório gerou aumento do déficit habitacional. Dados da Fundação João Pinheiro (FJP, 2018) referentes ao ano de 2015 indicaram um déficit habitacional de 303.822 unidades no Estado do Ceará; desse total, $89,2 \%$ se referem à faixa de renda até 3 salários mínimos. O déficit habitacional é categorizado por meio de diversos elementos. Citamos aqui os mais abrangentes: a) domicílios com ônus de excessivo aluguel (141.388 unidades [46,5\%]); b) habitação precária (73.568 unidades [24,2\%]); c) situação de coabitação familiar (72.908 unidades [24,0\%]); e d) adensamento excessivo de domicílios ocupados (14.759 unidade [4,8\%]) (FJP, 2018).

\section{O Conjunto Residencial Pedro Raimundo da Cruz}

O Município de Barbalha, segundo dados do relatório da Demanda Habitacional no Brasil (DHB, 2011), elaborado pela Caixa Econômica Federal, apresentou com base no Censo 2000 demanda de 1.541 unidades habitacionais.

Nesse cenário, as políticas públicas habitacionais aplicadas ao território barbalhense constituíram um instrumento de auxílio para amenizar os problemas ressaltados pelos dados estatísticos. Em 2017 foram entregues 600 unidades de habitação social, dentre elas as do Conjunto Residencial Pedro Raimundo da Cruz, localizado no Sítio Brejão - ou bairro Barro Branco, novo nome dado à localidade após a formalização de seu processo de urbanização.

O conjunto habitacional se situa a $11 \mathrm{~km}$ do centro de Barbalha e apresenta características de área rural e deficiências na oferta de serviços públicos. O que se observa in loco está em claro desacordo com os critérios da Lei n. 11.977 (2009). 
O primeiro ponto a destacar é o acesso a esse conjunto habitacional, que se dá unicamente pela rodovia CE-293. Ao sair da via mantida pelo Estado do Ceará é preciso percorrer cerca de $800 \mathrm{~m}$ até as residências. Vale ressaltar que o terreno do empreendimento foi doado pela Prefeitura de Barbalha (Site Miséria, n.d.), não sendo possível confrontar a lógica de escolha com o plano diretor do município, bem não se localizou a documentação relativa ao processo de doação' .

Em seguida, constata-se que o local do empreendimento seguiu a lógica da conversão de uma área rural (Sítio Brejão) em uma área urbana (bairro Barro Branco):

No seu entorno verifica-se o predomínio de áreas verdes e espaços vazios sem uso comum, seguido por uso agrícola e por último o residencial, isto repassa aos moradores, a sensação de insegurança e isolamento (Pessoa, 2016, p. 110).

Figura 1. Conjunto Residencial Pedro Raimundo da Cruz, em Barbalha-CE.

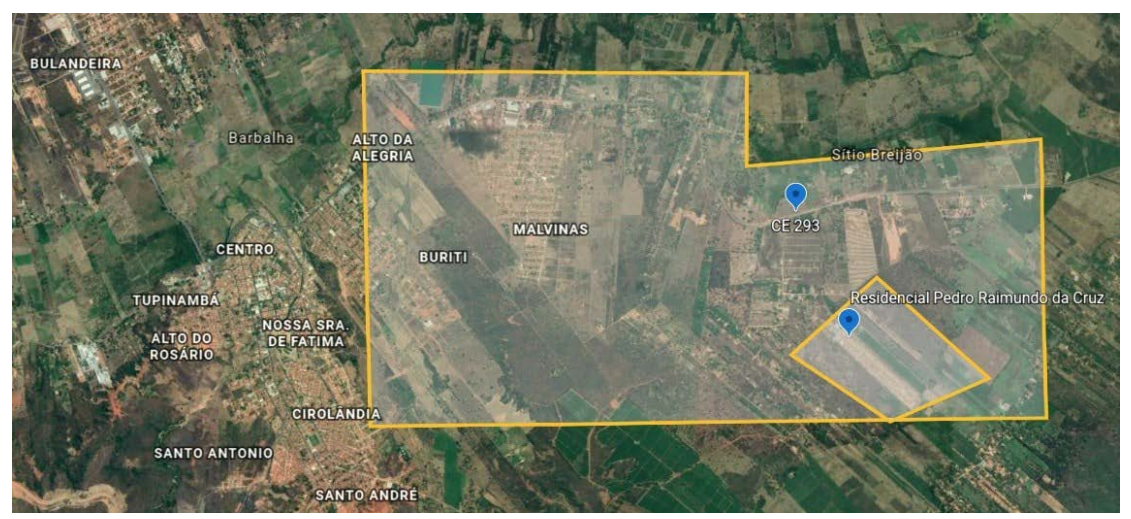

Fonte: Acervo pessoal dos autores.

As figuras 1 e 2 ilustram o afastamento desse local, caracterizado pela distância entre o Conjunto Residencial Pedro Raimundo da Cruz e os principais bairros do Município de Barbalha. 
Figura 2. Imagem ampliada do Conjunto Residencial Pedro Raimundo da Cruz, em Barbalha-CE.

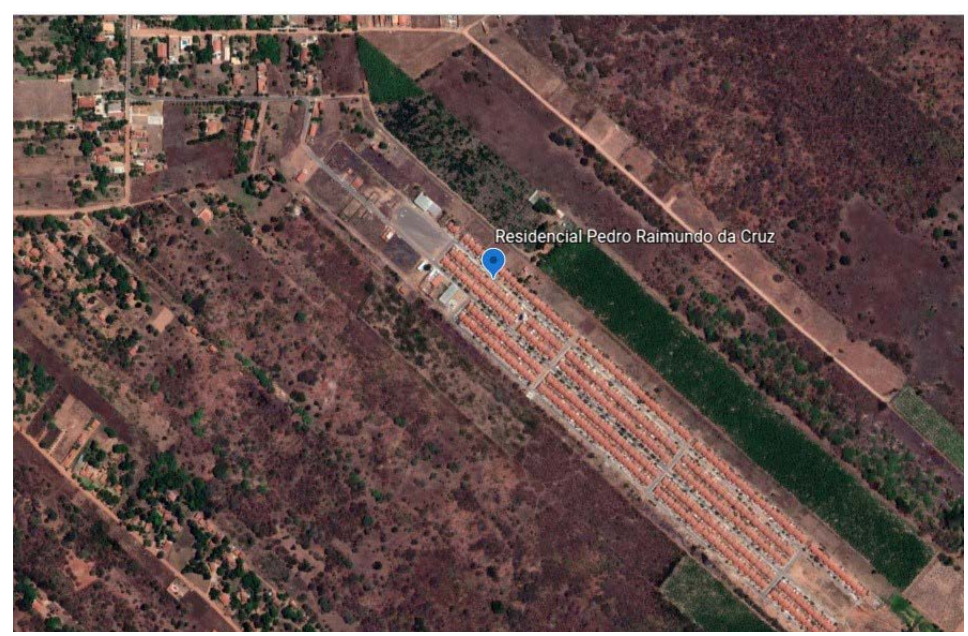

Fonte: Acervo pessoal dos autores.

A comparação entre a literatura consultada e as imagens coletadas por meio das técnicas de georreferenciamento dá conta da problemática aludida nas seções anteriores. Os dados demonstram quão distante se encontra o empreendimento residencial do centro do município (que concentra a malha de serviços públicos e privados oferecidos aos seus habitantes). Ao mesmo tempo, ao contrário do que dispõe a Lei n. 11.977 (2009), o entorno do residencial não se caracteriza como zona urbana (é composto majoritariamente por áreas rurais e de plantação).

Na Figura 1, observamos bairros típicos da zona urbana do Município de Barbalha à esquerda: a) Centro; b) Tupinambá; c) Alto do Rosário; d) Nossa Senhora de Fátima; e) Cirolândia; f) Santo Antonio; e g) Santo André. No ponto diametralmente oposto se encontra a "nova zona urbana" - o bairro Barro Branco, apenas formalmente efetivado como tal.

As figuras 3 e 4 apresentam as vias de acesso ao Conjunto Residencial Pedro Raimundo da Cruz. A Figura 3 mostra uma via estadual de fluxo de veículos de pequeno, médio e grande porte, sem estrutura para o trânsito de pedestres. E a Figura 4 expõe a precariedade da via de acesso às residências: não há calçamento ou projeto urbanístico para a área em uso. 
Figura 3. Único acesso ao Conjunto Residencial Pedro Raimundo da Cruz pela rodovia CE-293.

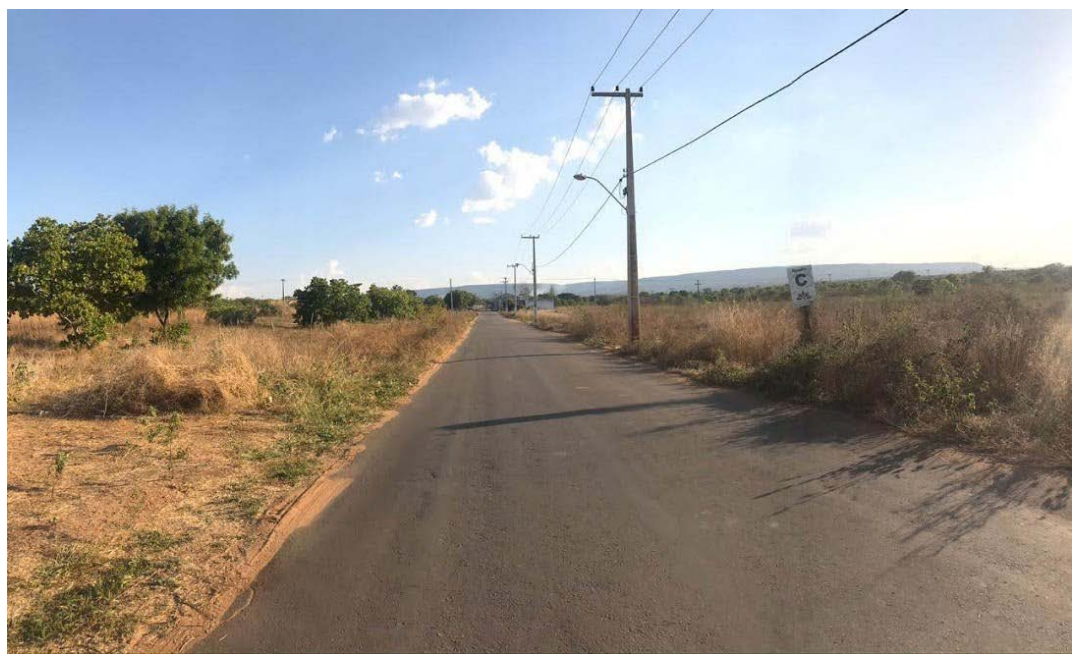

Fonte: Acervo pessoal dos autores.

Figura 4. Entrada do Conjunto Residencial Pedro Raimundo da Cruz, a 800 m da rodovia CE-293.

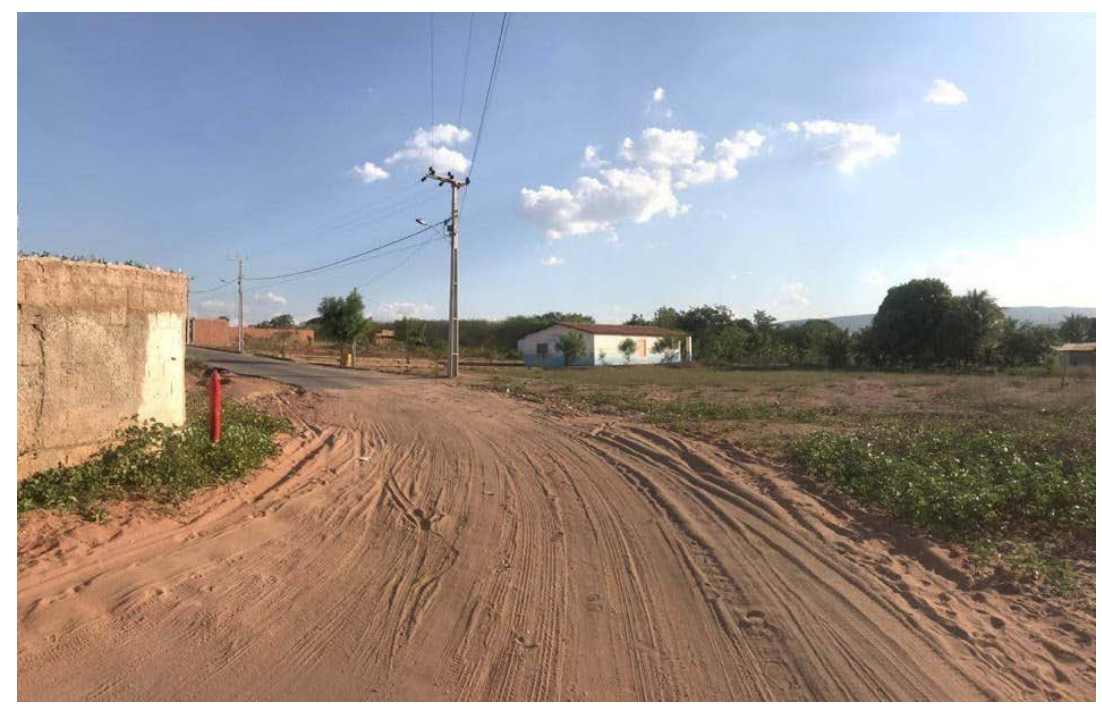

Fonte: Acervo pessoal dos autores.

A única escola existente na comunidade (Figura 5) oferece apenas a Educação Infantil. As crianças e os adolescentes só têm acesso aos demais níveis de ensino se deslocando para os bairros mais próximos do centro de Barbalha. A carência de espaços de lazer e convivência também é uma realidade. Os equipamentos à disposição da comunidade para esse fim se mostram insuficientes e demandam manutenção adequada (Figura 6). 
Figura 5. Centro de Educação Infantil no Conjunto Residencial Pedro Raimundo da Cruz.

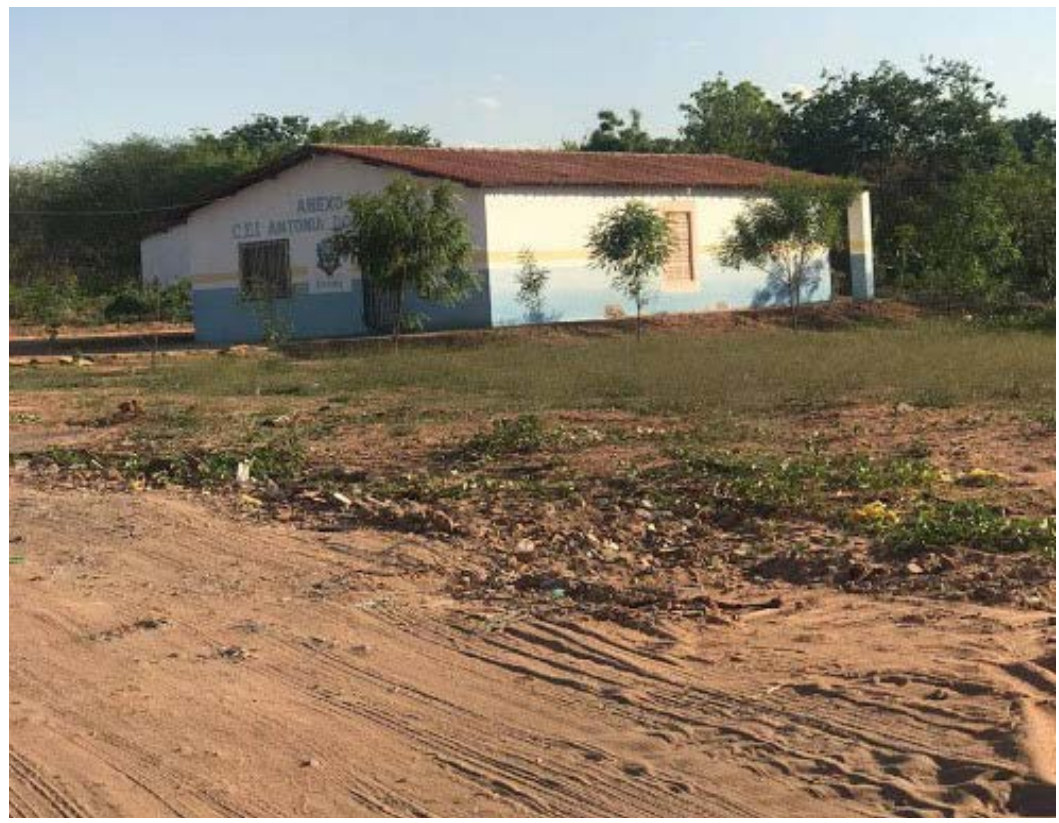

Fonte: Acervo pessoal dos autores.

Figura 6. Espaço de lazer comunitário Centro de Referência e Assistência Social.

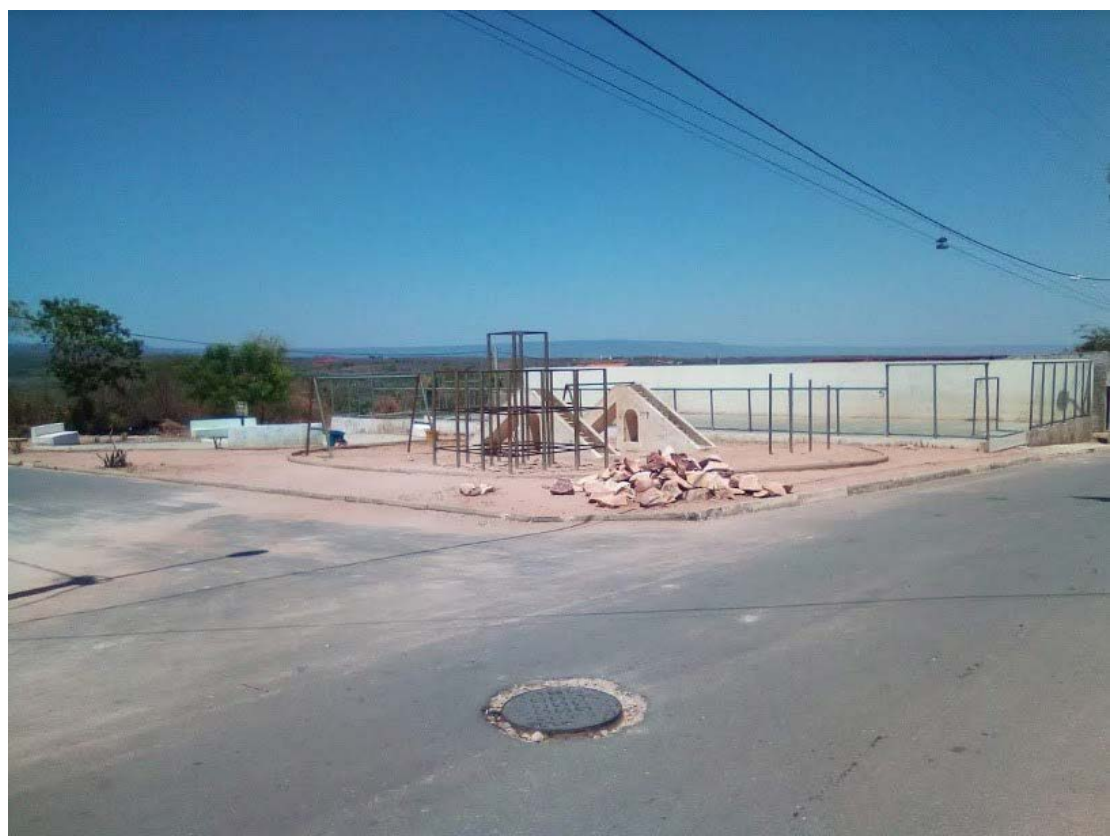

Fonte: Acervo pessoal dos autores. 
O Município de Barbalha segue a tendência de segregação social que o programa Minha Casa Minha Vida tem disseminado e intensificado em todo o território nacional. Os moradores ocupam o espaço física e simbolicamente, sendo apresentados pelo poder público como "beneficiários", mas, a despeito do ponto de vista formal e dos termos técnicos adotados, eles guardam lembranças, desejos e expectativas de um futuro melhor.

A próxima seção analisa essa problemática.

\section{Quem fala? A política habitacional e seus sujeitos}

Recorrendo a uma abordagem qualiquantitativa para o estudo de caso sobre o Município de Barbalha, inicialmente, adotamos como meta a realização de uma amostragem de $10 \%$ das casas do Conjunto Residencial Pedro Raimundo da Cruz, buscando apreender a percepção dos beneficiários do programa Minha Casa Minha Vida em contato com moradores de um empreendimento residencial.

Contudo, mediante visitas, observamos in loco que cerca de $30 \%$ do total de residências se encontravam sem uso regular (estavam fechadas ou em estado de abandono). Assim, decidimos subtrair do total o percentual de casas fechadas, chegando ao universo de 420 imóveis, e aplicamos o questionário em 10\% desse total. Dentre as 42 casas visitadas, conseguimos aplicar o instrumento de pesquisa em 20 casas; nas demais, os moradores se dispuseram a conversar, mas sem o compromisso de permitir a divulgação dos dados obtidos.

Foram estabelecidas algumas variáveis para a avaliação da política habitacional no campo de investigação: a) perfil socioeconômico dos moradores; b) percepção dos moradores quanto às condições de acesso aos equipamentos básicos no conjunto habitacional; c) percepção dos moradores quanto às condições de acesso aos equipamentos básicos em sua moradia anterior; e d) comparação entre as despesas básicas antes e depois da ocupação da residência no Conjunto Residencial Pedro Raimundo da Cruz.

A identificação do perfil socioeconômico dos moradores busca caracterizar quem são esses beneficiários do programa habitacional, enfocando a classe social para a qual essa política foi implantada. A Tabela 1 apresenta as principais características socioeconômicas observadas no Conjunto Residencial Pedro Raimundo da Cruz. 
Tabela 1. Perfil socioeconômico dos moradores do

Conjunto Residencial Pedro Raimundo da Cruz.

\begin{tabular}{|c|c|c|}
\hline \multicolumn{2}{|l|}{ CARACTERIZAÇÃO DAS FAMÍLIAS } & \multirow{2}{*}{$\begin{array}{l}\text { RESIDENCIAL } \\
\text { PEDRO RAIMUNDO CRUZ } \\
95 \%\end{array}$} \\
\hline Sexo do Proprietário (a) & Feminino & \\
\hline Faixa etária do proprietário (a) & $\begin{array}{l}25 \text { a } 29 \\
30 \text { a } 35 \\
40 \text { a } 55 \\
\text { mais de } 65 \text { anos }\end{array}$ & $\begin{array}{l}15 \% \\
35 \% \\
40 \% \\
10 \%\end{array}$ \\
\hline Nível de escolaridade & $\begin{array}{l}\text { Analfabeto } \\
\text { Ensino Fundamental } \\
\text { Ensino Médio }\end{array}$ & $\begin{array}{l}5 \% \\
60 \% \\
35 \%\end{array}$ \\
\hline Número de Residentes Adultos & $\begin{array}{l}01 \text { adulto } \\
01 \text { a } 02 \text { adultos } \\
03 \text { a } 05 \text { adultos } \\
\text { mais de } 05 \text { adultos }\end{array}$ & $\begin{array}{l}20 \% \\
60 \% \\
10 \% \\
10 \%\end{array}$ \\
\hline Número de Filhos & $\begin{array}{l}01 \text { filho } \\
01 \text { a } 02 \text { filhos } \\
03 \text { a } 05 \text { filhos } \\
\text { mais de } 05 \text { filhos }\end{array}$ & $\begin{array}{l}30 \% \\
25 \% \\
40 \% \\
5 \%\end{array}$ \\
\hline $\begin{array}{l}\text { Quantidade de pessoas que } \\
\text { trabalham na casa }\end{array}$ & $\begin{array}{l}01 \text { pessoa } \\
02 \text { pessoas } \\
\text { nenhuma }\end{array}$ & $\begin{array}{l}45 \% \\
15 \% \\
40 \% \\
\end{array}$ \\
\hline Tipo de Trabalho & $\begin{array}{l}\text { Formal } \\
\text { Informal }\end{array}$ & $\begin{array}{l}35 \% \\
65 \%\end{array}$ \\
\hline Renda média familiar & $\begin{array}{l}\text { Até meio salário mínimo } \\
\text { Meio a } 01 \text { salário mínimo } \\
\text { de } 01 \text { a } 02 \text { salários mínimos }\end{array}$ & $\begin{array}{l}40 \% \\
45 \% \\
15 \%\end{array}$ \\
\hline $\begin{array}{l}\text { Recebe algum benefício do } \\
\text { Governo }\end{array}$ & $\begin{array}{l}\text { Sim } \\
\text { Não }\end{array}$ & $\begin{array}{l}80 \% \\
20 \%\end{array}$ \\
\hline
\end{tabular}

Fonte: Elaborada pelos autores.

As famílias que moram nesse conjunto habitacional apresentam características muito semelhantes. Em sua grande maioria, as mulheres são chefes de família e sua idade varia entre 30 e 55 anos. O nível de escolaridade se concentra no Ensino Fundamental.

A maior parte dos núcleos familiares é composta por 4 ou 5 pessoas. Quando indagadas sobre a estrutura de seu imóvel, todas elas afirmaram estar satisfeitas com o tamanho, que comporta seus familiares, mas vale destacar que há inúmeros tipos de famílias nesse conjunto habitacional, com variada quantidade de moradores em cada residência.

Outra característica marcante se refere à renda e ao desemprego. Uma parte significativa desses moradores vivem com até 1 salário mínimo, de origem informal, e recebem algum tipo de benefício dos programas governamentais de transferência de 
renda. Um dado que demanda análise aprofundada é o índice de $40 \%$ de respondentes que não exercem qualquer tipo de atividade de trabalho (formal ou informal).

A política habitacional proporcionou moradia enquanto estrutura, contudo, mostram-se necessárias ações em outros níveis para uma efetiva melhoria da condição social. A Tabela 2 compara a percepção dos respondentes relativa ao Conjunto Residencial Pedro Raimundo da Cruz e sua moradia anterior.

Tabela 2. Comparação da percepção dos moradores quanto ao Conjunto Residencial Pedro Raimundo da Cruz e à sua moradia anterior.

\begin{tabular}{l|l|l|l}
\hline \multicolumn{2}{l}{$\begin{array}{l}\text { Percepções comparativa dos moradores do } \\
\text { conjunto habitacional quanto as condições de } \\
\text { acesso aos equipamentos urbanos: }\end{array}$} & \multicolumn{2}{l}{ Conjunto atual } \\
\hline \multirow{3}{*}{ Transporte } & Ótimo & $0 \%$ & $25 \%$ \\
& Bom & $20 \%$ & $65 \%$ \\
& Regular & $30 \%$ & $0 \%$ \\
& Ruim & $50 \%$ & $10 \%$ \\
\hline \multirow{4}{*}{ Atendimento Médico } & Ótimo & $5 \%$ & $20 \%$ \\
& Bom & $50 \%$ & $60 \%$ \\
& Regular & $25 \%$ & $15 \%$ \\
& Ruim & $15 \%$ & $5 \%$ \\
\hline \multirow{4}{*}{ Acesso à Escola } & Ótimo & $0 \%$ & $5 \%$ \\
& Bom & $25 \%$ & $65 \%$ \\
& Regular & $35 \%$ & $25 \%$ \\
& Ruim & $40 \%$ & $5 \%$ \\
\hline \multirow{3}{*}{ Sensação de Segurança } & Ótimo & $0 \%$ & $0 \%$ \\
& Bom & $65 \%$ & $90 \%$ \\
& Regular & $20 \%$ & $10 \%$ \\
& Ruim & $15 \%$ & $0 \%$ \\
\hline
\end{tabular}

Fonte: Elaborada pelos autores.

Quando indagados sobre seu local de origem, os respondentes intercalam suas respostas entre a zona urbana e a zona rural. Genericamente, os dados indicam maior nível de satisfação com o acesso a serviços públicos na moradia anterior e os principais problemas relatados quanto à atual realidade habitacional se referem ao acesso a equipamentos essenciais para o bem-estar social.

Os transportes são caracterizados como ruins por $50 \%$ dos respondentes e $30 \%$ deles o consideram regular. Uma das principais razões de insatisfação é o valor das passagens. As pessoas que buscam seu meio de sobrevivência na informalidade relatam que, muitas vezes, deixam de trabalhar por não poderem custear as tarifas do transporte público. O acesso aos transportes é considerado inadequado por $80 \%$ dos respondentes, o que demonstra a ineficiência da política habitacional nesse sentido. 
O acesso às escolas é outro problema relevante do local. As mães relatam superlotação e indefinição dos horários dos ônibus escolares. Segundo os respondentes, os ônibus buscam as crianças muito cedo, tendo em vista o horário de início das aulas, e elas voltam para casa muito depois do término das atividades escolares. Um fato que contribui para a superlotação é o uso dos ônibus escolares para outros fins (p. ex., transportar gratuitamente pessoas que não podem pagar as tarifas do transporte público convencional).

Um anexo de posto de saúde foi instalado na comunidade no início de 2019. Esse imóvel conta com estrutura considerada inadequada e não havia médico atendendo na localidade em alguns meses. Na data em que este artigo foi redigido, 1 médico proporcionava consultas básicas nessa unidade de saúde, além de 1 enfermeira e 1 técnica de enfermagem. Nesse sentido, os respondentes se mostraram satisfeitos, mas apontaram a necessidade de implementação de uma estrutura adequada que conte com médicos especialistas. Tal afirmação leva em conta o fato do Município de Barbalha se destacar no Estado do Ceará como polo de serviços de saúde.

A percepção dos respondentes não ficou clara quanto no quesito segurança. Quando indagados sobre a segurança no local de sua moradia anterior, 90\% dos respondentes a consideraram satisfatória, ao passo que a segurança no local do conjunto habitacional foi considerada boa por $60 \%$ deles e $35 \%$ a consideraram regular ou ruim. Os moradores ressaltaram a necessidade de aumentar as rondas policiais no entrono do empreendimento residencial e afirmaram que os problemas relativos à segurança sempre ocorriam em outra rua, nunca na sua rua - essa tendência também demanda análise aprofundada.

A última variável compara as despesas básicas antes e depois da ocupação da residência no Conjunto Residencial Pedro Raimundo da Cruz.

Esse quesito não havia sido considerado na primeira versão do instrumento de pesquisa, contudo, os próprios respondentes solicitaram que a equipe de pesquisadores registrasse esses dados. Tal iniciativa nos levou a refletir sobre o abandono legal e institucional da comunidade, que viu nos pesquisadores, sujeitos com potencial de intervenção política, a possiblidade de levar as necessidades locais ao conhecimento dos gestores públicos.

Percebeu-se uma tendência de aumento das despesas com energia elétrica e água na comunidade (Tabela 3). 
Tabela 3. Comparação das despesas básicas no Conjunto Residencial Pedro Raimundo da Cruz e na moradia anterior.

\begin{tabular}{|c|c|c|c|}
\hline $\begin{array}{c}\text { Apontamento } \\
\text { comparativo sobre o } \\
\text { aumento das despesas } \\
\text { básicas dos moradores do } \\
\text { conjunto habitacional: }\end{array}$ & & Conjunto atual & Bairro de Origem \\
\hline Gastos com Água & $\begin{array}{l}\$ 20 \text { a } \$ 25 \\
\$ 35 \text { a } \$ 50 \\
\$ 50 \text { a } \$ 100 \\
\$ 100 \text { a } \$ 150 \\
\$ 150 \text { a } \$ 220 \\
\text { acima de } \$ 220\end{array}$ & $\begin{array}{l}10 \% \\
15 \% \\
20 \% \\
25 \% \\
20 \% \\
10 \%\end{array}$ & $\begin{array}{l}55 \% \\
35 \% \\
5 \% \\
5 \% \\
0 \\
0\end{array}$ \\
\hline Gastos com Energia & $\begin{array}{l}\$ 20 \text { a } \$ 25 \\
\$ 35 \text { a } \$ 50 \\
\$ 50 \text { a } \$ 100 \\
\$ 100 \text { a } \$ 150 \\
\$ 150 \text { a } \$ 220 \\
\text { acima de } \$ 220\end{array}$ & $\begin{array}{l}0 \\
5 \% \\
50 \% \\
10 \% \\
30 \% \\
5 \%\end{array}$ & $\begin{array}{l}35 \% \\
50 \% \\
10 \% \\
5 \% \\
0 \\
0\end{array}$ \\
\hline Valor da Parcela da casa & $\begin{array}{l}\$ 20 \text { a } \$ 25 \\
\$ 35 \text { a } \$ 45 \\
\$ 45 \text { a } \$ 55 \\
\$ 55 \text { a } \$ 65 \\
\text { acima de } \$ 65\end{array}$ & $\begin{array}{l}35 \% \\
55 \% \\
0 \\
10 \% \\
5 \%\end{array}$ & \\
\hline
\end{tabular}

Fonte: Elaborada pelos autores.

Novamente se identifica disparidade entre os critérios estabelecidos em lei e a prática cotidiana dessa política habitacional. Considerando o perfil social de seus beneficiários, os custos da energia elétrica e da água aumentaram sem justificativa - eis outro problema que demanda análise aprofundada.

Vale apontar que os serviços de abastecimento de energia elétrica e água constituem um tema sensível na realidade brasileira. Mediante observação in loco, constatou-se: a) a ausência de registros de medição do consumo; b) a existência de ligações clandestinas para consumo sem pagamento das contas; c) a pactuação do pagamento em conjunto das contas; e d) o uso compartilhado dos serviços em nome de um único morador.

Em vista do perfil socioeconômico dos moradores, de suas percepções quanto à política habitacional a eles destinada, dos valores cobrados pelo abastecimento de água e energia elétrica e das carências de acesso adequado aos serviços de transporte e educação, podemos afirmar que há, no mínimo, um descompasso entre as disposições legais e os serviços efetivamente oferecidos aos beneficiários do programa Minha Casa Minha Vida.

A arena de enfrentamento entre aqueles que constroem sua subjetivação a partir do conceito de lar e aqueles que veem a política de habitação como formalidade para fins 
estatísticos constitui um tema de interesse sociológico e histórico e, como tal, demanda abordagem interdisciplinar.

Cada indivíduo tem nome, história, desejos, percepções, direitos - e destes ele sabe que não é mero destinatário, mas sujeito.

Esta fala é impactante por representar a realidade de milhões brasileiros:

Prometeram a nós que quando a gente viesse pra cá nossa vida ia melhorar, mas jogaram nós aqui e nos abandonaram. Melhorou foi nada, aqui é o inferno, não vou me embora porque minha casa é aqui! (Diário de campo, outubro de 2019)

\section{Conclusões}

Analisamos o programa Minha Casa Minha Vida sob a perspectiva do Município de Barbalha, enfocando, sobretudo, as percepções dos moradores assistidos por essa política habitacional no Conjunto Residencial Raimundo Pedro da Cruz.

Consideramos pertinente estabelecer uma comparação entre a política habitacional posta em prática no Município de Barbalha e em Viçosa, Salvador, Londrina e Ponta de Pedra. Constatamos haver uma consonância no programa Minha Casa Minha Vida relativa não só às condições estruturais de moradia, mas, também, à segregação social imposta aos chamados "beneficiários".

Por meio do quadro comparativo entre diferentes regiões do país, observam-se semelhanças nos objetivos e no modus operandi da política habitacional nos municípios brasileiros, cujos problemas práticos refletem tanto a má gestão por parte do poder público quanto a dinâmica estrutural de segregação social da pobreza no país.

Vale destacar que os critérios de escolha dos terrenos destinados aos empreendimentos do programa Minha Casa Minha Vida versam interesses privados ao submeter seus beneficiários a moradoria em locais de difícil acesso e sem infraestrutura adequada. Tal cenário demonstra a extensão da vulnerabilidade das populações que ainda vivenciam a falta de moradia no Brasil.

Para garantir o direito à moradia das populações de baixa renda, o programa Minha Casa Minha Vida implica uma redistribuição do ordenamento urbano municipal, com implementação de uma infraestrutura básica, porém, no Brasil do século XXI, os direitos constitucionais se tornaram meras promessas e refletem mais os programas de governo do que as políticas de Estado.

Como conclusões temporárias, podemos afirmar que, em Barbalha, o programa Minha Casa Minha Vida caracteriza um claro descompasso entre as disposições legais e os serviços efetivamente oferecidos aos beneficiários, pois o empreendimento habitacional 
se situa em área afastada do centro urbano do município, comprometendo diretamente as condições de vida da comunidade em questão. Mostra-se importante salientar que a moradia digna não se resume a um conjunto de paredes, é indispensável viabilizar a efetivação de outras políticas públicas de modo integrado (como as relativas a saúde, lazer, transporte e educação).

Neste artigo, destacamos as lacunas do programa Minha Casa Minha Vida enquanto política habitacional, criticando a desterritorialização promovida ao realocar populações sem considerar os aspectos simbólicos da convivência em comunidade. O modelo adotado envolve uma urbanização desigual que inviabiliza o efetivo acesso dos beneficiários aos serviços públicos e privados disponíveis em sua cidade, promovendo e ratificando uma dinâmica estrutural de segregação social da pobreza.

Mediante diálogo com os moradores do Conjunto Residencial Pedro Raimundo da Cruz, constatamos que o termo morar vai muito além de ter uma casa, implicando tradições, culturas e condições de convivência, que são criadas ao longo do tempo. Quando isso não é levado em conta, os indivíduos são "coisificados" e se veem em meio a um doloroso processo de reencontro, reconexão e reconstrução de histórias e experiências (que pode vir a não se tornar uma realidade concreta).

Este artigo dialoga com os aspectos inerentes à sonegação de direitos sociais das populações de baixa renda contempladas pelas políticas públicas. Buscou-se discutir a efetivação do programa Minha Casa Minha Vida no Município de Barbalha de modo a estimular novos questionamentos e espera-se que futuras pesquisas dessa natureza ouçam as comunidades, que veem nos pesquisadores, sujeitos com potencial de intervenção política, a possiblidade de levar as necessidades locais ao conhecimento dos gestores públicos.

\section{Referências bibliográficas}

Andrade, E. S. J. (2011, maio). Síntese histórica das políticas habitacionais no Brasil (1964 a 2010): avanços de antigas propostas e retorno a velhas práticas. Anais ENANPUR, 14(1), 1-20.

BRASIL. Secretaria de Direitos Humanos da Presidência da República Direito à moradia adequada. - Brasília: Coordenação Geral de Educação em SDH/PR, Direitos Humanos, Secretaria Nacional de Promoção e Defesa dos Direitos Humanos, 2013.

CAIXA ECONÔMICA FEDERAL. Demanda habitacional no Brasil / Caixa Econômica Federal. -

Brasília: CAIXA, 2011. Disponível em http://www.caixa.gov.br/Downloads/habitacao-documentos-gerais/demanda_habitacional.pdf

Acesso em 28/07/2020 
Carvalho, A. W. B., \& Stephan, Í. I. C. (2016). Eficácia social do programa Minha Casa Minha Vida: discussão conceitual e reflexão a partir de um caso empírico. Cadernos Metrópole, 18(35), 283-307. Carvalho, J. M. (1987). Os bestializados. São Paulo, SP: Companhia das Letras.

Constituição da República Federativa do Brasil, de 5 de outubro de 1988. (1988). Brasília, DF.

Emenda Constitucional n. 90, de 15 de setembro de 2015. (2015). Dá nova redação ao art. 6 da

Constituição Federal, para introduzir o transporte como direito social. Brasília, DF.

COSTA, Beatriz Sousa; VENÂNCIO, Stephanie Rodrigues. (2016). A função social da cidade e o direito à moradia digna como pressupostos do desenvolvimento urbano sustentável. Revista Direito Ambiental e sociedade, v. 6, n. 2, 106-136. Disponível em file:///D:/LOCAIS\%20DOS\%20ARQUIVOS/ Downloads/3481-17523-1-PB\%20(1).pdf

Acesso em 31 de julho de 2020.

Fundação João Pinheiro. (2018). Déficit habitacional no Brasil 2015. Recuperado de http://fjpdados. fjp.mg.gov.br/deficit/\#: :text=Os\%20resultados\%20mostram\%20que,domic\%C3\%ADlios\%20 particulares\%20permanentes\%20e\%20improvisados

Gonçalves, N. C. (2011). O fogo não está morto: engenhos de rapadura do Cariri cearense como uma referência cultural na perspectiva das políticas públicas do último quartel do século XX (Dissertação de Mestrado). Universidade Federal de Minas Gerais, Belo Horizonte, MG.

Holston, J. (2013). Cidadania insurgente: disjunções da democracia e da modernidade no Brasil. São Paulo, SP: Companhia das Letras.

Instituto Brasileiro de Geografia e Estatística. (2010). Panorama: Brasil/Ceará/Barbalha. Recuperado de https://cidades.ibge.gov.br/brasil/ce/barbalha/panorama

Lei n. 11.977, de 7 de julho de 2009. (2009). Dispõe sobre o Programa Minha Casa, Minha

Vida - PMCMV e a regularização fundiária de assentamentos localizados em áreas urbanas; altera o Decreto-Lei n. 3.365, de 21 de junho de 1941, as Leis ns. 4.380, de 21 de agosto de 1964, 6.015, de 31 de dezembro de 1973, 8.036, de 11 de maio de 1990, e 10.257, de 10 de julho de 2001, e a Medida Provisória n. 2.197-43, de 24 de agosto de 2001; e dá outras providências. Brasília, DF.

Lei Complementar Estadual n. 78, de 26 junho de 2009. (2009). Dispõe sobre a criação da Região Metropolitana do Cariri, cria o Conselho de Desenvolvimento e Integração e o Fundo de

Desenvolvimento e Integração da Região Metropolitana do Cariri - FDMC, altera a composição de microrregiões do Estado do Ceará e dá outras providências. Fortaleza, CE.

Menezes, V. M. O. (2015). Percepções de beneficiários sobre a efetividade do programa Minha Casa Minha Vida. Revista de Ciências Humanas, 49(1), 145-164.

Neves, F.C. (1995). Curral dos Bárbaros: os Campos de Concentração no. Ceará (1915 e 1932). Revista Brasileira de História, 15 (29), 93-122. 
Pagani, E. B. S. (2013). Território, desigualdade e cidadania: o programa Minha Casa, Minha Vida em Londrina. Serviço Social em Revista, 16(1), 89-113.

Pessoa, T. M. (2016). Implantação do programa Minha Casa Minha Vida nos municípios de Crato, Juazeiro do Norte e Barbalha: arranjos institucionais e condições de inserção urbana (Dissertação de Mestrado). Universidade Federal do Ceará, Fortaleza, CE.

Rangel, J. A., \& Montoia, G. R. M. (2015, maio). O programa Minha Casa Minha Vida nas pequenas cidades da Amazônia: a dicotomia entre as políticas públicas e a realidade no município de Ponta de Pedras-PA. Anais ENANPUR, 16(1), 1-20.

Santos, M. (1990). São Paulo: metrópole corporativa e fragmentada. São Paulo, SP: Nobel.

Sevcenko, N. (2003). A Revolta da Vacina: mentes insanas em corpos rebeldes. São Paulo, SP: Scipione.

Site Miséria. (n.d.). Recuperado de https://www.miseria.com.br

SILVA, Marlon Lima da; TOURINHO, Helena Lúcia Zagury. O Banco Nacional de Habitação e o Programa Minha Casa Minha Vida: duas políticas habitacionais e uma mesma lógica locacional. Cadernos Metrópole, [S.L.], v. 17, n. 34, p. 401-417, nov. 2015. FapUNIFESP (SciELO). http://dx.doi. org/10.1590/2236-9996.2015-3405.

WILHAN SANTIN (Londrina). Folha de São Paulo (ed.). Programa Minha Casa, Minha Vida ergue

'minicidade' isolada. 2012. Disponível em: https://m.folha.uol.com.br/cotidiano/2012/10/

1172645-programa-minha-casa-minha-vida-ergue-minicidade-isolada.shtml. Acesso em: 28 jul. 2020

\section{Para citar este artigo}

\section{Norma A - ABNT}

BARRETO, P. L. N.; MATOS, C. S. Minha casa é aqui! Percepções dos beneficiários do Minha Casa Minha Vida. Conhecer: Debate entre o Público e o Privado, v. 10, n. 25, p. 11-34, 2020.

\section{Norma B - APA}

barreto, P. L. N. \& matos, C. S. (2020). Minha casa é aqui! Percepções dos beneficiários do Minha Casa Minha Vida. Conhecer: Debate entre o Público e o Privado, 10(25), 11-34.

\section{Norma C - Vancouver}

barreto PLN, matos CS. Minha casa é aqui! Percepções dos beneficiários do Minha Casa Minha Vida. Conhecer: Debate entre o Público e o Privado [Internet]. 2020 [cited Ago 03, 2020];10(25):11-34. Available from: https://revistas.uece.br/index.php/revistaconhecer/article/view/3036 